\title{
Clinical significance of oxidative stress for untreated patients with diffuse large B-cell lymphoma
}

\author{
HIROSHI NAKAMURA ${ }^{1}$, TAKESHI HARA ${ }^{1,2}$, RYOKO MABUCHI ${ }^{1}$, TAKURO MATSUMOTO ${ }^{1}$, \\ NOBUHIKO NAKAMURA ${ }^{1}$, SORANOBU NINOMIYA ${ }^{1}$, JUNICHI KITAGAWA ${ }^{1}$, \\ NOBUHIRO KANEMURA ${ }^{1}$, YUSUKE KITO ${ }^{3}$, TSUYOSHI TAKAMI ${ }^{3}$, TATSUHIKO MIYAZAKI ${ }^{4}$, \\ TAMOTSU TAKEUCHI $^{3}$, MASAHITO SHIMIZU ${ }^{1}$ and HISASHI TSURUMI ${ }^{1,2}$

\footnotetext{
${ }^{1}$ First Department of Internal Medicine, Gifu University Graduate School of Medicine, Gifu 501-1194;

${ }^{3}$ Department of Pathology and Translational Research, Gifu University Graduate School of Medicine;

${ }^{4}$ Department of Pathology, Gifu University Hospital, Gifu 501-1194, Japan
} \\ ${ }^{2}$ Department of Hematology, Matsunami General Hospital, Kasamatsu-cho, Hashima-gun, Gifu 501-6062;
}

Received May 15, 2020; Accepted July 14, 2021

DOI: $10.3892 / \mathrm{mco} .2021 .2437$

\begin{abstract}
Oxidative stress serves an important role in carcinogenesis. The present study investigated the clinical significance of oxidative stress as a prognostic factor for diffuse large B-cell lymphoma (DLBCL). The participants comprised 55 consecutive patients with DLBCL. A commercially available derivatives of reactive oxygen metabolites (d-ROMs) test kit was used to assess oxidant levels. Similarly, a commercially available biological antioxidant potential (BAP) test was used to assess antioxidant levels. The antioxidative/oxidative stress ratio was calculated as d-ROMs/BAP. The median serum concentration of d-ROMs was $425 \mu \mathrm{M}$. The levels of d-ROMs were significantly higher in patients with DLBCL than in healthy volunteers $(\mathrm{P}<0.01)$. The complete remission (CR) rates in patients with $\mathrm{d}$-ROMs $<425$ and $\geq 425 \mu \mathrm{M}$ were 81.5 and $85.7 \%$, respectively [not significant (NS)]. The 3 -year overall survival (OS) rates for patients with d-ROMs $<425$ and $\geq 425 \mu \mathrm{M}$ were 67.2 and $72.0 \%$, respectively (NS). The median BAP was $2,002 \mu \mathrm{M}$. The CR rates of patients with BAP $<2,002$ and $\geq 2,002 \mu \mathrm{M}$ were 77.8 and $88.9 \%$, respectively (NS). The 3 -year OS rates of patients with BAP $<2,002$ and $\geq 2,002 \mu \mathrm{M}$ were 60.9 and $75.9 \%$, respectively (NS). No significant difference in the d-ROMs/BAP ratio was observed between groups. Multivariate analysis revealed that $\mathrm{d}$-ROMs were an independent prognostic factor for progression-free survival.
\end{abstract}

Correspondence to: Professor Hisashi Tsurumi, First Department of Internal Medicine, Gifu University Graduate School of Medicine, 1-1 Yanagido, Gifu 501-1194, Japan

E-mail: htsuru@gifu-u.ac.jp

Key words: diffuse large B-cell lymphoma, non-Hodgkin's lymphoma, oxidative stress, derivatives of reactive oxygen metabolites test, biological antioxidant potential test

\section{Introduction}

Diffuse large B-cell lymphoma (DLBCL) constitutes 25-30\% of adult non-Hodgkin lymphomas in developed countries, with higher percentages in developing countries. This pathology is more common among elderly individuals (1). Many investigators have investigated prognostic factors for DLBCL. We have previously reported various prognostic factors for DLBCL (2-13). Today, the most reliable and established prognostic factors for DLBCL are the International Prognostic Index (IPI) and the revised IPI (R-IPI) $(14,15)$. Usually, the pathogenesis of cancer cells is considered to involve high levels of reactive oxygen species (ROS) because of metabolic and signaling abnormalities. ROS are believed to promote cancer progression through the activation of oncogenic signaling pathways and damage to DNA (16). Oxidative stress can be defined as an imbalance between the pro- and anti-oxidant responses of the cell. Oxidative stress may also result from overproduction of ROS or insufficient neutralization of ROS by anti-oxidants (17).

The measured concentration is considered to be directly proportional to the quantity of reactive oxygen metabolites (ROMs) affected by active ROS and free radicals. Measuring ROMs thus enables quantitative evaluation of the condition of oxidative stress throughout the human body (18). Quantification of derivatives of ROMs (d-ROMs) is a simple method for detecting hydroperoxide levels (19), and clinical trials have shown that the d-ROMs test is useful for evaluating oxidative stress $(19,20)$. Biological antioxidant potential (BAP) can be measured simultaneously.

ROS function may be a key to many impaired biological processes, including cancers. Various investigators have reported that oxidative stress plays an important role in carcinogenesis, including for lung cancer (21-23), hepatocellular carcinoma $(24,25)$, colorectal cancer $(26)$, and ovarian cancer (27). However, we could only identify one report that investigated associations between oxidative stress and hematological malignancies (28). Here, we aimed to 
investigate the role of oxidative stress as a prognostic factor for DLBCL in a retrospective analysis.

\section{Patients and methods}

Study design. This retrospective study was organized by Gifu University Graduate School of Medicine (Gifu, Japan). Participants were patients with untreated CD20-positive DLBCL at Gifu University Hospital. The initial cohort comprised 55 consecutive patients histologically diagnosed with DLBCL between December 2012 and March 2016 according to the 2008 classification of the World Health Organization (WHO) (29). All follow-up data were updated as of April 12, 2019. Thirty-six healthy volunteers (10 men, 26 women) served as a control group. All patients provided written informed consent to participate in the study according to the guidelines of our institution and the Declaration of Helsinki. Samples were acquired during routine diagnostic assessments. This study was approved by the institutional review board at our institution (Gifu University Graduate School of Medicine, approval no. 2018-003).

Oxidative stress andother determinations. Oxidative stress was investigated by measuring serum hydroperoxide concentrations according to the d-ROMs test (Diacron International srl) using a free radical elective evaluator, FREE (Diacron International srl), as described previously $(19,20,24,30)$. Similarly, a commercially available BAP test was used to assess antioxidant levels (Diacron International srl), as described previously (31). The antioxidative/oxidative stress ratio was calculated as BAP/d-ROMs. Peripheral white blood cell count (WBC) and serum concentrations of lactate dehydrogenase (LDH), soluble interleukin 2 receptor (sIL-2R), and C-reactive protein (CRP) were determined on admission.

Treatment strategy. Patients received 6-8 cycles of either $\mathrm{R}-\mathrm{CHOP}$ or R-THP-COP.These regimens comprised rituximab ( $\mathrm{R} ; 375 \mathrm{mg} / \mathrm{m}^{2}$, as a 4-h intravenous (i.v.) drip infusion on day 1), cyclophosphamide (C; $750 \mathrm{mg} / \mathrm{m}^{2}$, as a 2-h i.v. drip infusion on day 3), doxorubicin $\left(\mathrm{H} ; 50 \mathrm{mg} / \mathrm{m}^{2}\right.$, as a $30-\mathrm{min}$ i.v. drip infusion on day 3 ) or tetrahydropyranyl-adriamycin (THP; $50 \mathrm{mg} / \mathrm{m}^{2}$, as a 30 -min i.v. drip infusion on day 3 ), vincristine $\left(\mathrm{O} ; 1.4 \mathrm{mg} / \mathrm{m}^{2}\right.$, maximal dose $2.0 \mathrm{mg}$ i.v. as a bolus over $5 \mathrm{~min}$ on day 3), and prednisolone [P; $100 \mathrm{mg}$ /day per os (p.o.) on days 3-7]. The R-THP-COP regimen included THP, an anthracycline derivative of doxorubicin reportedly offering lower cardiotoxicity than doxorubicin $(32,33)$. Our previous prospective randomized study found no significant differences in remission or survival rates between CHOP and THP-COP therapies (34). In addition, we reported the utility and safety of R-THP-COP from a single-arm phase II study $(35,36)$ and a randomized phase III study (37). Granulocyte colony-stimulating factor (G-CSF) was administered at the discretion of the physician. Patients with a bulky mass received radiotherapy after chemotherapy. Patients who relapsed or in whom disease progressed after R-CHOP or R-THP-COP, and those who were resistant to R-CHOP or R-THP-COP underwent salvage chemotherapy with R-P-IMVP-16/CBDCA (rituximab, methylprednisolone, ifosfamide, methotrexate, etoposide, and carboplatin) $(38,39)$. A proportion of patients with refractory or relapsed DLBCL who responded to R-P-IMVP-16/CBDCA received high-dose chemotherapy followed by autologous peripheral blood stem cell transplantation.

Response criteria. Treatment response was evaluated after the 2nd, 4th, 6th, and final cycles of chemotherapy. Treatment responses were categorized after repeated physical examinations, radiological studies, gallium scintigraphy, fluorodeoxyglucose-positron emission tomography, and bone-marrow evaluation according to the 2007 International Working Group Criteria (40).

Statistical analysis. Data are expressed as median. Differences in mean values were tested using the nonparametric Mann-Whitney U-test and Kruskal-Wallis test. For comparisons among $\geq 3$ groups, differences in mean values were tested using the nonparametric Kruskal-Wallis test followed by Dunn's post hoc test. Spearman's correlation coefficient was used to test correlations between d-ROMs and other serum markers. Effects of d-ROMs and other serum markers of survival were examined by univariate analyses using the log-rank test based on Kaplan and Meier methods (41). Multivariate analysis was performed using the Cox proportional-hazards regression technique to define the prognostic significance of selected variables including $\mathrm{d}-\mathrm{ROM}$ and $\mathrm{BAP}$. Values of $\mathrm{P}<0.05$ were considered significant.

\section{Results}

Patient characteristics. A total of 55 patients were enrolled in the present study. Table I summarizes the clinical characteristics of patients (median age, 72 years; range, 36-93 years). Thirty-six healthy volunteers were enrolled (median age, 50.5 years; range, 25-82 years) (Table I). A significant difference in age was identified between DLBCL patients and controls $(\mathrm{P}<0.01)$.

d-ROMs and BAP in DLBCL patients and healthy controls. Median d-ROMs concentration was significantly increased among healthy volunteers $(329 \mu \mathrm{M})$ compared to DLBCL patients $(425 \mu \mathrm{M} ; \mathrm{P}<0.001)$ (Fig. 1A). In contrast, median BAP values were significantly decreased in DLBCL patients $(2,002 \mu \mathrm{M})$ compared to healthy volunteers $(2,352 \mu \mathrm{M} ; \mathrm{P}<0.001)$ (Fig. 1B). In addition, the d-ROMs/BAP ratio was significantly higher in DLBCL patients (0.203) than in healthy volunteers (0.137; P<0.001) (Fig. 1C). Cut-offs were $425 \mu \mathrm{M}$ for d-ROMs, $2,002 \mu \mathrm{M}$ for BAP, and 0.203 for d-ROM/BAP, all of which essentially represented median values for all DLBCL patients.

Correlations between d-ROMs and other markers in DLBCL patients. Table II shows correlations between d-ROMs, BAP, d-ROMs/BAP and other markers in DLBCL patients. No significant correlation existed between d-ROMs and clinical stage in DLBCL patients. Significant correlations existed between d-ROMs and LDH $(\mathrm{P}<0.01)$, between d-ROMs and sIL-2R $(\mathrm{P}<0.001)$, between $\mathrm{d}-\mathrm{ROMs}$ and IPI $(\mathrm{P}<0.05)$, between $\mathrm{d}-\mathrm{ROMs}$ and $\mathrm{B}$ symptoms $(\mathrm{P}<0.001)$, and between d-ROMs and bulky disease $(\mathrm{P}<0.01)$ in patients with DLBCL. Significant correlations existed between BAP and IPI $(\mathrm{P}<0.001)$. No significant correlations existed between BAP and clinical 
Table I. Clinical characteristics of the patients with diffuse large B cell lymphoma $(n=55)$.

\begin{tabular}{|c|c|}
\hline Variable & No. $(\%)$ \\
\hline \multicolumn{2}{|l|}{ Sex } \\
\hline Male & $36(65.0)$ \\
\hline Female & $19(35.0)$ \\
\hline \multicolumn{2}{|l|}{ Age, years } \\
\hline$<61$ & $7(12.7)$ \\
\hline$\geq 61$ & $48(87.3)$ \\
\hline \multicolumn{2}{|l|}{ PS } \\
\hline 0,1 & $46(84.0)$ \\
\hline $2-4$ & $9(16.0)$ \\
\hline \multicolumn{2}{|l|}{ LDH } \\
\hline Normal & $19(35.00$ \\
\hline Increased & $36(65.0)$ \\
\hline \multicolumn{2}{|l|}{ Extranodal sites } \\
\hline 0,1 & $37(67.3)$ \\
\hline$\geq 2$ & $18(32.7)$ \\
\hline \multicolumn{2}{|l|}{ Clinical stage } \\
\hline $\mathrm{I} / \mathrm{II}$ & $17(31.0)$ \\
\hline III/IV & $38(69.0)$ \\
\hline \multicolumn{2}{|l|}{ B symptom } \\
\hline Absence & $13(24.0)$ \\
\hline Presence & $42(76.0)$ \\
\hline \multicolumn{2}{|l|}{ Bulky disease } \\
\hline Absence & $47(85.0)$ \\
\hline Presence & $8(15.0)$ \\
\hline \multicolumn{2}{|l|}{ sIL-2R, U/ml } \\
\hline$<2,000$ & $38(69.0)$ \\
\hline$\geq 2,000$ & $17(31.0)$ \\
\hline \multicolumn{2}{|l|}{ IPI } \\
\hline Low & $11(20.0)$ \\
\hline Low-intermediate & $13(24.0)$ \\
\hline High-intermediate & $21(38.0)$ \\
\hline High & $10(18.0)$ \\
\hline \multicolumn{2}{|l|}{ R-IPI } \\
\hline Very good & $1(1.8)$ \\
\hline Good & $24(43.6)$ \\
\hline Poor & $30(54.50$ \\
\hline
\end{tabular}

OS, overall survival; PFS, progression-free survival; d-ROM, derivatives of reactive oxygen; BAP, biological antioxidant potential; PS, performance status; LDH, lactate dehydrogenase; sIL-2R, soluble interleukin 2 receptor; IPI, international prognostic index; R-IPI, revised IPI.

stage, between BAP and sIL-2R, between BAP and B symptoms, between BAP and $\mathrm{LDH}$, between BAP and performance status (PS) or between BAP and bulky disease in patients with DLBCL. Significant correlations existed between d-ROM/BAP and clinical stage $(\mathrm{P}<0.05)$, between $\mathrm{d}-\mathrm{ROM} / \mathrm{BAP}$ and sIL-2R $(\mathrm{P}<0.0001)$, between $\mathrm{d}-\mathrm{ROM} / \mathrm{BAP}$ and IPI $(\mathrm{P}<0.05)$, and
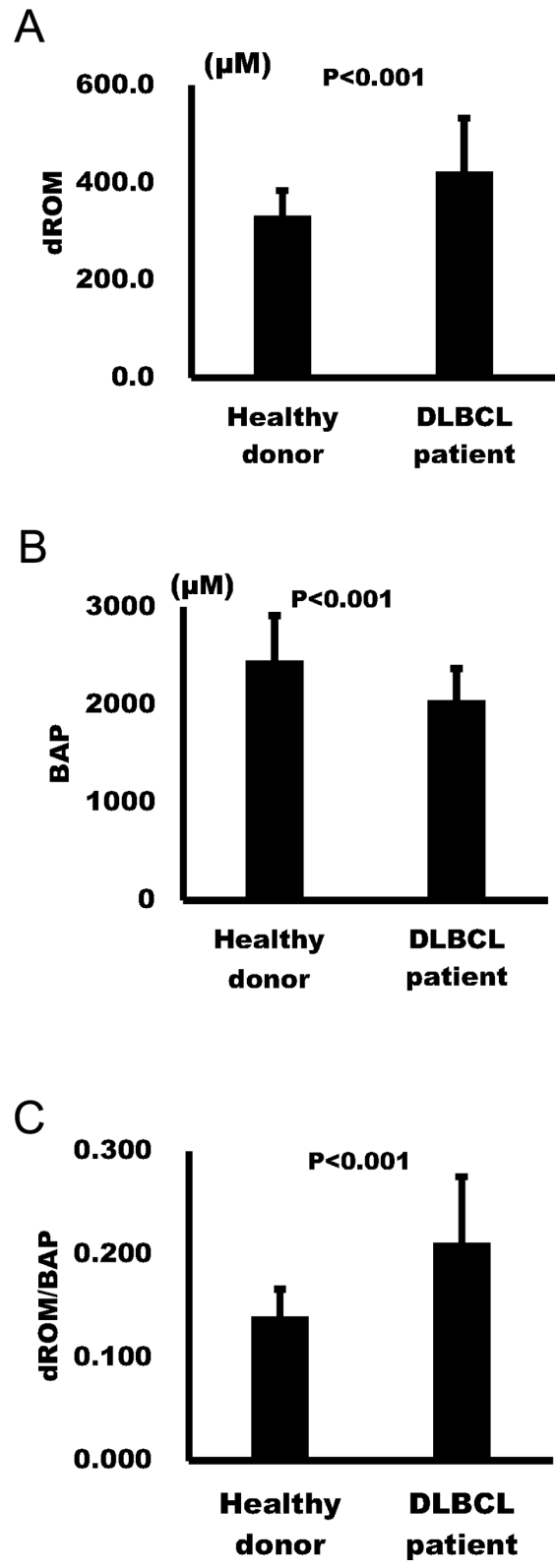

Figure 1. Levels of d-ROMs, BAP and d-ROMs/BAP ratio in patients with DLBCL and healthy controls. (A) Median concentration of d-ROMs was significantly increased in patients with DLBCL $(425 \mu \mathrm{M})$ compared with healthy volunteers (329 $\mu \mathrm{M} ; \mathrm{P}<0.001)$. (B) Median BAP concentration was significantly decreased in patients with DLBCL $(2,002 \mu \mathrm{M})$ compared with healthy volunteers $(2,352 \mu \mathrm{M} ; \mathrm{P}<0.001)$. (C) Median d-ROM/BAP ratio was significantly higher in patients with DLBCL $(0.203)$ than in healthy volunteers $(0.137 ; \mathrm{P}<0.001)$. Error bars indicate the standard deviation. d-ROMs, derivatives of reactive oxygen metabolites; BAP, biological antioxidant potential; DLBCL, diffuse large B-cell lymphoma.

between $\mathrm{d}-\mathrm{ROM} / \mathrm{BAP}$ and $\mathrm{B}$ symptoms $(\mathrm{P}<0.001)$ in patients with DLBCL.

Analysis of response to therapy. Table III shows the results of analysis of complete remission (CR) rates in DLBCL patients. The CR rate for all DLBCL patients was $83.6 \%$. $\mathrm{CR}$ rates of patients with $\mathrm{d}-\mathrm{ROM}<425$ and $\geq 425 \mu \mathrm{M}$ were 81.5 and $85.7 \%$, respectively [not significant (NS)]. CR rates of patients with BAP $<2,002$ and $\geq 2,002 \mu \mathrm{M}$ were 77.8 and $88.9 \%$, respectively (NS). CR rates of patients with d-ROM/BAP $<0.203$ and $\geq 0.203$ were 88.9 and $77.8 \%$, 
Table II. Association between oxidative stress markers and other markers in diffuse large B cell lymphoma.

\begin{tabular}{|c|c|c|c|c|c|c|c|c|c|}
\hline \multirow[b]{2}{*}{ Variable } & \multicolumn{3}{|c|}{ d-ROM $(\mu \mathrm{M})$} & \multicolumn{3}{|c|}{$\mathrm{BAP}(\mu \mathrm{M})$} & \multicolumn{3}{|c|}{ d-ROM/BAP } \\
\hline & Median & Range & P-value & Median & Range & P-value & Median & Range & P-value \\
\hline \multicolumn{10}{|l|}{ Sex } \\
\hline Male & 426 & $262-660$ & \multirow[t]{2}{*}{0.3427} & 1999 & $1468-2653$ & \multirow[t]{2}{*}{0.8527} & 0.20 & $0.124-0.432$ & \multirow[t]{2}{*}{0.7028} \\
\hline Female & 381 & $171-658$ & & 2126 & $1571-2812$ & & 0.21 & $0.100-0.360$ & \\
\hline \multicolumn{10}{|l|}{ Age, years } \\
\hline$<61$ & 415 & $303-660$ & \multirow[t]{2}{*}{0.6483} & 2213 & $1640-2609$ & \multirow[t]{2}{*}{0.2450} & 0.23 & $0.129-0.253$ & \multirow[t]{2}{*}{0.6483} \\
\hline$\geq 61$ & 426 & $171-658$ & & 1998 & $1468-2812$ & & 0.20 & $0.100-0.432$ & \\
\hline \multicolumn{10}{|l|}{ PS } \\
\hline 0,1 & 402 & $171-660$ & \multirow[t]{2}{*}{0.3011} & 2129 & $1538-2812$ & \multirow[t]{2}{*}{0.0248} & 0.19 & $0.100-0.360$ & \multirow[t]{2}{*}{0.0248} \\
\hline $2-4$ & 497 & $280-634$ & & 1728 & $1468-2457$ & & 0.29 & $0.181-0.432$ & \\
\hline \multicolumn{10}{|l|}{ LDH } \\
\hline Normal & 364 & $247-474$ & \multirow[t]{2}{*}{0.0372} & 2175 & $1626-2563$ & \multirow[t]{2}{*}{0.4515} & 0.17 & $0.100-0.266$ & \multirow[t]{2}{*}{0.0491} \\
\hline Increased & 440 & $171-660$ & & 1981 & $1484-2812$ & & 0.23 & $0.101-0.432$ & \\
\hline \multicolumn{10}{|l|}{ Extranodal sites } \\
\hline 0,1 & 435 & $171-660$ & \multirow[t]{2}{*}{0.6307} & 1998 & $1468-2609$ & \multirow[t]{2}{*}{0.2911} & 0.19 & $0.101-0.432$ & \multirow[t]{2}{*}{0.5036} \\
\hline$\geq 2$ & 434 & $247-622$ & & 2113 & $2113-2812$ & & 0.21 & $0.100-0.297$ & \\
\hline \multicolumn{10}{|l|}{ Clinical stage } \\
\hline $\mathrm{I} / \mathrm{II}$ & 378 & $269-474$ & 0.0618 & 2178 & $1571-2572$ & 0.0900 & 0.17 & $0.124-0.245$ & 0.0469 \\
\hline III/IV & 435 & $171-660$ & & 1981 & $1468-2812$ & & 0.22 & $0.100-0.432$ & \\
\hline B symptom & & & & & & & & & \\
\hline Absence & 378 & $171-660$ & 0.0054 & 2138 & $1538-2653$ & 0.3043 & 0.19 & $0.100-0.293$ & 0.0021 \\
\hline Presence & 553 & $321-658$ & & 1908 & $1468-2812$ & & 0.29 & $0.165-0.432$ & \\
\hline Bulky disease & & & & & & & & & \\
\hline Absence & 389 & $171-658$ & 0.0089 & 2059 & $1538-2812$ & 0.4118 & 0.19 & $0.100-0.360$ & 0.0018 \\
\hline Presence & 552 & $381-660$ & & 1736 & $1468-2609$ & & 0.26 & $0.242-0.432$ & \\
\hline sIL-2R, U/ml & & & & & & & & & \\
\hline$<2,000$ & 378 & $247-660$ & 0.0112 & 2168 & $1538-2812$ & 0.0121 & 0.18 & $0.100-0.266$ & 0.0066 \\
\hline$\geq 2,000$ & 507 & $171-658$ & & 1825 & $1468-2543$ & & 0.28 & $0.101-0.432$ & \\
\hline IPI & & & & & & & & & \\
\hline Low & 364 & $292-474$ & 0.0394 & 2203 & $1782-2563$ & 0.0023 & 0.17 & $0.129-0.228$ & 0.0122 \\
\hline Low-intermediate & 389 & $269-660$ & & 2126 & $1697-2609$ & & 0.19 & $0.124-0.266$ & \\
\hline High-intermediate & 415 & $171-658$ & & 1773 & $1468-2482$ & & 0.24 & $0.1-0.432$ & \\
\hline High & 521 & $343-622$ & & 2195 & $1825-2812$ & & 0.22 & $0.129-0.297$ & \\
\hline R-IPI & & & & & & & & & \\
\hline Very good $(0 \text { points })^{\mathrm{a}}$ & 378 & 378 & 0.1507 & 2213 & 2213 & 0.0956 & 0.17 & 0.171 & 0.0470 \\
\hline Good (1 and 2 points) & 376 & $269-660$ & & 2176 & $1697-2609$ & & 0.18 & $0.124-0.266$ & \\
\hline Poor (3-5 points) & 442 & $171-658$ & & 1904 & $1468-2812$ & & 0.23 & $0.10-0.432$ & \\
\hline
\end{tabular}

${ }^{a}$ The Very good group included only 1 patient. d-ROM, derivatives of reactive oxygen metabolities; BAP, biological antioxidant potential; PS, performance status; LDH, lactate dehydrogenase; sIL-2R, soluble interleukin 2 receptor; IPI, international prognostic index; R-IPI, revised IPI.

respectively (NS). No factors were significantly associated with CR rates in DLBCL patients.

Oxidative stress as a prognostic factor in DLBCL. Table IV shows the results of univariate analyses for survival rates in DLBCL. Median follow-up period was 26.2 months. Three-year overall survival (OS) rates for patients with d-ROMs $<425$ and $\geq 425 \mu \mathrm{M}$ were 67.2 and $72.0 \%$, respectively (NS, Fig. 2A). Three-year OS rates for patients with BAP $<2,002$ and $\geq 2,002 \mu \mathrm{M}$ were 60.9 and $75.9 \%$, respectively (NS, Fig. 2B). Three-year OS rates for patients with d-ROMs/BAP $<0.203$ and $\geq 0.203$ were 65.5 and $71.6 \%$, respectively (NS, Fig. 2C). Other factors associated with significantly worse OS were poor PS (>1) and unfavorable IPI (high intermediate and high risk groups). Three-year progression-free survival (PFS) rates for patients with $\mathrm{d}-\mathrm{ROMs}<425$ and $\geq 425 \mu \mathrm{M}$ were 66.7 and $65.1 \%$, respectively (NS, Fig. 2D). Three-year PFS rates for patients with BAP $<2,002$ and $\geq 2,002 \mu \mathrm{M}$ were 54.0 and $73.7 \%$, respectively (NS, Fig. 2E). Three-year PFS rates for patients with d-ROMs/BAP $<0.203$ and $\geq 0.203$ were 66.7 and $65.1 \%$, respectively (NS, Fig. $2 \mathrm{~F}$ ). Other factors associated with significantly worsened PFS were advanced stage (III or IV), and unfavorable IPI (HI and $\mathrm{H}$ risk groups) (Table I).

Multivariate analyses for OS and PFS (Table V). Multivariate analyses identified age, PS, clinical stage, and sIL-2R as 
Table III. Univariate analysis of remission rate in diffuse large B cell lymphoma.

\begin{tabular}{|c|c|c|c|}
\hline \multirow[b]{2}{*}{ Variable } & \multirow[b]{2}{*}{ Total no. of patients } & \multicolumn{2}{|c|}{$\mathrm{CR}$} \\
\hline & & $\%$ & P-value \\
\hline All patients & 55 & 83.6 & \\
\hline \multicolumn{4}{|l|}{ Sex } \\
\hline Male & 36 & 78.9 & 0.4947 \\
\hline Female & 19 & 86.1 & \\
\hline \multicolumn{4}{|l|}{ Age, years } \\
\hline$<61$ & 7 & 85.7 & 0.8736 \\
\hline$\geq 61$ & 48 & 83.3 & \\
\hline \multicolumn{4}{|l|}{ PS } \\
\hline 0,1 & 46 & 84.8 & 0.6034 \\
\hline $2-4$ & 9 & 77.8 & \\
\hline \multicolumn{4}{|l|}{$\mathrm{LDH}$} \\
\hline Normal & 19 & 94.7 & 0.106 \\
\hline Increased & 36 & 77.8 & \\
\hline \multicolumn{4}{|l|}{ Extranodal sites } \\
\hline 0,1 & 37 & 86.5 & 0.9662 \\
\hline$\geq 2$ & 18 & 77.8 & \\
\hline \multicolumn{4}{|l|}{ Clinical stage } \\
\hline $\mathrm{I} / \mathrm{II}$ & 17 & 88.2 & 0.6198 \\
\hline III/IV & 38 & 81.6 & \\
\hline \multicolumn{4}{|l|}{ B symptom } \\
\hline Absence & 13 & 81.0 & 0.3335 \\
\hline Presence & 42 & 92.3 & \\
\hline \multicolumn{4}{|l|}{ Bulky disease } \\
\hline Absence & 47 & 87.2 & 0.0804 \\
\hline Presence & 8 & 62.5 & \\
\hline \multicolumn{4}{|l|}{ sIL-2R, U/ml } \\
\hline$<2,000$ & 38 & 81.6 & 0.5375 \\
\hline$\geq 2,000$ & 17 & 88.2 & \\
\hline \multicolumn{4}{|l|}{ IPI } \\
\hline Low & 11 & 100.0 & 0.0577 \\
\hline Low-intermediate & 13 & 92.3 & \\
\hline High-intermediate & 21 & 66.7 & \\
\hline High & 10 & 90.0 & \\
\hline \multicolumn{4}{|l|}{ R-IPI } \\
\hline Very good & 1 & 100.0 & 0.0982 \\
\hline Good & 24 & 91.7 & \\
\hline Poor & 30 & 76.7 & \\
\hline \multicolumn{4}{|l|}{ d-ROM } \\
\hline$<425 \mu \mathrm{M}$ & 22 & 81.5 & 0.6714 \\
\hline$\geq 425 \mu \mathrm{M}$ & 24 & 85.7 & \\
\hline \multicolumn{4}{|l|}{ BAP } \\
\hline$\geq 2,002 \mu \mathrm{M}$ & 24 & 88.9 & 0.2488 \\
\hline$<2,002 \mu \mathrm{M}$ & 21 & 77.8 & \\
\hline \multicolumn{4}{|l|}{ d-ROM/BAP } \\
\hline$<0.203$ & 24 & 88.9 & 0.2488 \\
\hline$\geq 0.203$ & 21 & 77.8 & \\
\hline
\end{tabular}

$\mathrm{CR}$, complete remission; d-ROM, derivatives of reactive oxygen metabolities; BAP, biological antioxidant potential; PS, performance status; $\mathrm{LDH}$, lactate dehydrogenase; sIL-2R, soluble interleukin 2 receptor; IPI, international prognostic index; R-IPI, revised IPI. 
Table IV. Univariate analysis of survival rate in diffuse large B cell lymphoma.

\begin{tabular}{|c|c|c|c|c|c|c|}
\hline \multirow[b]{2}{*}{ Variable } & \multicolumn{3}{|c|}{3 year-OS } & \multicolumn{3}{|c|}{3 year-PFS } \\
\hline & No. of patients & $\%$ & P-value & No. of patients & $\%$ & P-value \\
\hline All patients & 55 & 69.3 & & 55 & 65.5 & \\
\hline \multicolumn{7}{|l|}{ Age, years } \\
\hline$<61$ & 7 & 100.0 & 0.1129 & 7 & 71.4 & 0.5840 \\
\hline$\geq 61$ & 48 & 58.1 & & 48 & 47.8 & \\
\hline \multicolumn{7}{|l|}{ PS } \\
\hline 0,1 & 46 & 76.1 & 0.0101 & 46 & 71.3 & 0.0940 \\
\hline $2-4$ & 9 & NR & & 9 & NR & \\
\hline \multicolumn{7}{|l|}{ LDH } \\
\hline Normal & 19 & 86.1 & 0.0541 & 19 & 89.1 & 0.0311 \\
\hline Increased & 36 & 50.2 & & 36 & 45.0 & \\
\hline \multicolumn{7}{|l|}{ Extranodal sites } \\
\hline 0,1 & 37 & 72.0 & 0.8239 & 37 & 70.8 & 0.4569 \\
\hline$\geq 2$ & 18 & 63.8 & & 18 & 53.9 & \\
\hline \multicolumn{7}{|l|}{ Clinical stage } \\
\hline $\mathrm{I} / \mathrm{II}$ & 17 & 87.8 & 0.3399 & 17 & 87.8 & 0.0433 \\
\hline III/IV & 38 & 61.6 & & 38 & 55.7 & \\
\hline \multicolumn{7}{|l|}{ B symptom } \\
\hline Absence & 13 & 64.9 & 0.2503 & 13 & 66.1 & 0.3018 \\
\hline Presence & 42 & 61.5 & & 42 & 48.5 & \\
\hline \multicolumn{7}{|l|}{ Bulky disease } \\
\hline Absence & 47 & 70.1 & 0.5217 & 47 & 71.1 & 0.1580 \\
\hline Presence & 8 & 37.5 & & 8 & 25.0 & \\
\hline \multicolumn{7}{|l|}{ sIL-2R, U/ml } \\
\hline$<2,000$ & 38 & 70.6 & 0.8837 & 38 & 70.6 & 0.7164 \\
\hline$\geq 2,000$ & 17 & 66.5 & & 17 & 54.5 & \\
\hline \multicolumn{7}{|l|}{ IPI } \\
\hline Low & 11 & 100.0 & 0.0382 & 11 & 100.0 & 0.0232 \\
\hline Low-intermediate & 13 & 82.1 & & 13 & 76.9 & \\
\hline High-intermediate & 21 & 52.7 & & 21 & 49.0 & \\
\hline High & 10 & 54.9 & & 10 & 43.8 & \\
\hline \multicolumn{7}{|l|}{ R-IPI } \\
\hline Very good & 1 & NR & 0.0533 & 1 & 100.0 & 0.0169 \\
\hline Good & 24 & 85.4 & & 24 & 82.9 & \\
\hline Poor & 30 & 54.9 & & 30 & 50.2 & \\
\hline \multicolumn{7}{|l|}{ d-ROM } \\
\hline$<425 \mu \mathrm{M}$ & 27 & 67.2 & 0.4369 & 27 & 66.7 & 0.4104 \\
\hline$\geq 425 \mu \mathrm{M}$ & 28 & 72.0 & & 28 & 65.1 & \\
\hline \multicolumn{7}{|l|}{ BAP } \\
\hline$\geq 2,002 \mu \mathrm{M}$ & 27 & 75.9 & 0.2510 & 27 & 73.7 & 0.2055 \\
\hline$<2,002 \mu \mathrm{M}$ & 27 & 60.9 & & 27 & 54.0 & \\
\hline \multicolumn{7}{|l|}{ d-ROM/BAP } \\
\hline$<0.203$ & 27 & 65.5 & 0.9217 & 27 & 60.2 & 0.8086 \\
\hline$\geq 0.203$ & 27 & 71.6 & & 27 & 70.4 & \\
\hline
\end{tabular}

OS, overall survival; PFS, progression-free survival; d-ROM, derivatives of reactive oxygen metabolities; BAP, biological antioxidant potential; PS, performance status; LDH, lactate dehydrogenase; sIL-2R, soluble interleukin 2 receptor; IPI, international prognostic index; R-IPI, revised IPI; NR, not reached. 

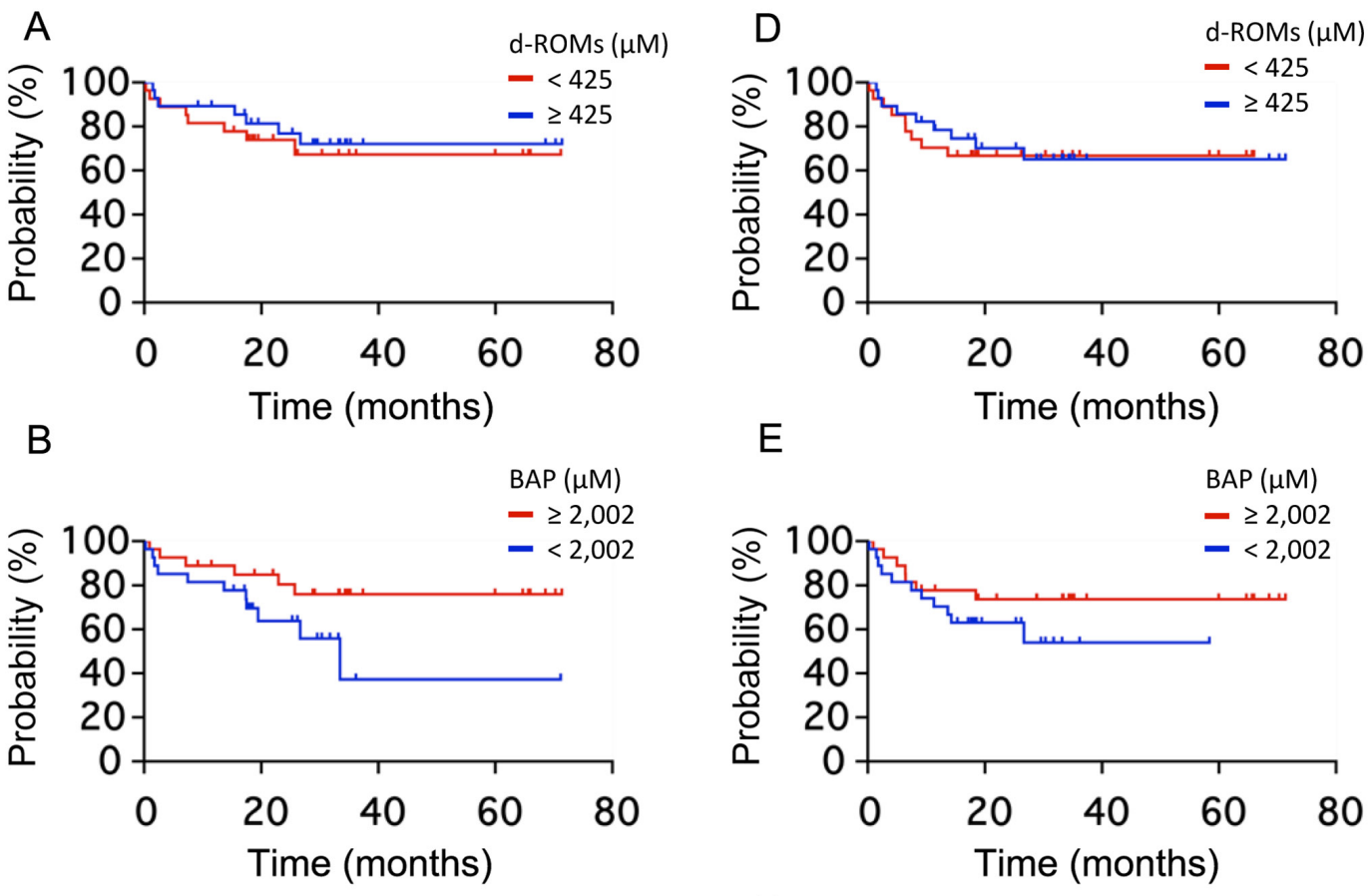

C

F
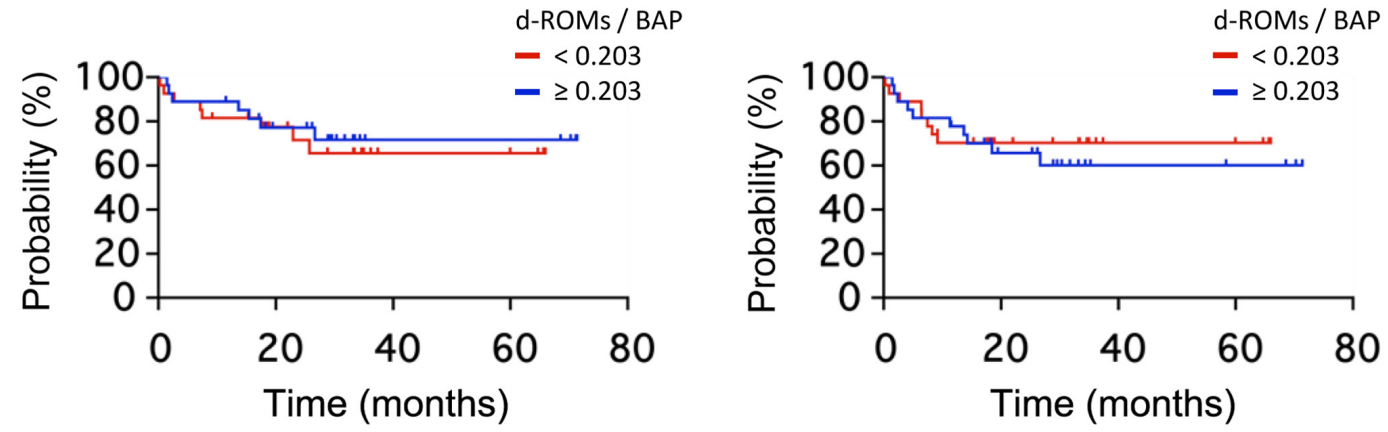

Figure 2. OS and PFS curves according to d-ROMs, BAP and d-ROMs/BAP ratio in patients with DLBCL. (A) 3-year OS rates for patients with d-ROMs $<425$ and $\geq 425 \mu \mathrm{M}$ were 67.2 and $72.0 \%$, respectively (NS). (B) 3-year OS rates for patients with BAP $<2,002$ and $\geq 2,002 \mu \mathrm{M}$ were 60.9 and $75.9 \%$, respectively (NS). (C) 3-year OS rates for patients with d-ROMs/BAP $<0.203$ and $\geq 0.203$ were 65.5 and $71.6 \%$, respectively (NS). (D) 3 -year PFS rates for patients with d-ROMs $<425$ and $\geq 425 \mu \mathrm{M}$ were 66.7 and $65.1 \%$, respectively (NS). (E) 3-year PFS rates for patients with BAP $<2,002$ and $\geq 2,002 \mu \mathrm{M}$ were 54.0 and $73.7 \%$, respectively (NS). (F) 3-year PFS rates for patients with d-ROMs/BAP $<0.203$ and $\geq 0.203$ were 66.7 and $65.1 \%$, respectively (NS). OS, overall survival; PFS, progression-free survival; d-ROMs, derivatives of reactive oxygen metabolites; BAP, biological antioxidant potential; DLBCL, diffuse large B-cell lymphoma; NS, not significant.

independent prognostic factors for OS, and LDH, clinical stage, and d-ROMs as independent prognostic factors for PFS.

\section{Discussion}

Oxidative stress might play an important role in carcinogenesis. Excessive production of ROS has been reported to cause damage to cellular macromolecules such as DNA (42), and can increase levels of various types of DNA damage, including DNA base damage and single- and double-strand breaks $(43,44)$. In addition, excessive production of ROS could interrupt the tumor cell signaling pathways, which are involved in cell growth and survival. This obstruction might lead to cancer promotion and progression. Indeed, many reports have shown that oxidative stress might play important roles in carcinogenesis for some malignancies (21-27). Tsukioka et al (21) reported preoperative serum levels of ROMs as a significant independent predictor of nodal involvement in patients with clinical stage I lung adenocarcinoma. Oxidative stress could be reasonably expected to impact the progression of lung cancer, because the lung is the organ most affected by increased oxidative stress. Gencer et al (23) reported that serum levels of ROMs were increased in patients with different types of lung cancers and speculated that serum levels of ROMs may offer an index parameter for lung cancer. The role of ROS in colorectal cancer was examined by Inokuma et al (26). They reported that serum ROS levels were elevated in proportion to tumor invasion and showed a significant positive correlation with tumor size. Suzuki et al (24) reported that hepatocellular carcinoma patients with increased levels of oxidative stress were prone to recurrence after curative treatment.

The present study found a significant difference in age between DLBCL patients and controls. A previous study reported that oxidative stress was associated with mortality in older ages (45). We could not exclude the potential impact of aging on the production of oxidative stressors. Generally, 
Table V. Multivariate analysis of OS and PFS in diffuse large B cell lymphoma.

\begin{tabular}{llcc}
\hline A, OS & & & \\
Variable & \multicolumn{1}{c}{ Comparison } & Hazard ratio & $95 \%$ CI \\
\hline Age & $<61$ vs. $\geq 61$ years & 3.54 & $0.40-2.67$ \\
PS & 0,1 vs. $2-4$ & 6.89 & $1.48-33.33$ \\
LDH & Normal vs. increased & 3.66 & $0.71-30.13$ \\
Extranodal sites & 0,1 vs. $\geq 2$ & 1.76 & $0.41-7.78$ \\
Clinical stage & I, II vs. III, IV & 9.11 & $1.42-97.47$ \\
B symptoms & Absence vs. presence & 6.88 & $0.87-81.02$ \\
Bulky disease & Absence vs. presence & 4.68 & $0.60-35.32$ \\
sIL-2R & $<2,000$ vs. $\geq 2,000 \mathrm{U} / \mathrm{ml}$ & 6.01 & $1.10-47.90$ \\
d-ROM & $<425$ vs. $\geq 425 \mu \mathrm{M}$ & 2.21 & 0.4440 \\
BAP & $<2,002$ vs. $\geq 2,002 \mu \mathrm{M}$ & 1.09 & 0.0189 \\
& & & 0.0680 \\
\end{tabular}

$\mathrm{B}, \mathrm{PFS}$

\begin{tabular}{|c|c|c|c|c|}
\hline Variable & Comparison & Hazard ratio & $95 \% \mathrm{CI}$ & P-value \\
\hline Age & $<61$ vs. $\geq 61$ years & 2.59 & $0.46-22.99$ & 0.3024 \\
\hline PS & 0,1 vs. $2-4$ & 2.41 & $0.61-8.43$ & 0.1974 \\
\hline $\mathrm{LDH}$ & Normal vs. increased & 9.30 & $1.78-69.13$ & 0.0069 \\
\hline Extranodal sites & 0,1 vs. $\geq 2$ & 1.69 & $0.56-5.12$ & 0.3448 \\
\hline Clinical stage & I, II vs. III, IV & 6.73 & $1.22-56.79$ & 0.0279 \\
\hline B symptoms & Absence vs. presence & 1.99 & $0.49-9.52$ & 0.3435 \\
\hline Bulky disease & Absence vs. presence & 3.97 & $0.87-18.42$ & 0.0747 \\
\hline sIL-2R & $<2,000 \mathrm{vs} . \geq 2,000 \mathrm{U} / \mathrm{ml}$ & 3.77 & $0.95-18.10$ & 0.0596 \\
\hline d-ROM & $<425$ vs. $\geq 425 \mu \mathrm{M}$ & 3.66 & $1.09-13.65$ & 0.0361 \\
\hline BAP & $<2,002$ vs. $\geq 2,002 \mu \mathrm{M}$ & 2.83 & $0.87-9.72$ & 0.0837 \\
\hline
\end{tabular}

Multivariate analysis was performed using the Cox proportional-hazards regression technique to define the prognostic significance of selected variables including d-ROM and BAP. OS, overall survival; PFS, progression-free survival; d-ROM, derivatives of reactive oxygen metabolities; BAP, biological antioxidant potential; PS, performance status; LDH, lactate dehydrogenase; sIL-2R, soluble interleukin 2 receptor; 95\% CI, 95\% confidence interval.

elderly individuals comprise the majority of DLBCL patients, and age represents an important prognostic factor for DLBCL. We suspected that the production of oxidative stress might affect not only the carcinogenesis of DLBCL but also the poor prognosis in elderly patients with DLBCL. One possibility is that d-ROMs, BAP, and d-ROMs/BAPratio might reflect the risk of inflammatory complications such as pneumonia in DLBCL patients. We cannot deny the possibility that inflammatory complications affected d-ROMs and BAP concentrations. When d-ROMs and BAP were measured in DLBCL patients on admission, no cases were complicated with inflammatory diseases such as pneumonia. Indeed, a significant correlation existed between d-ROMs and B symptoms.

In the present study, d-ROMs in DLBCL patients were increased compared to those in healthy volunteers. Similarly, BAP in DLBCL patients was decreased compared to that in healthy volunteers. As a result, the d-ROMs/BAP ratio was significantly higher in DLBCL patients than in healthy volunteers. These results suggest that oxidative stress contributes to carcinogenesis in DLBCL by damaging DNA. Our study could not find any positive correlation between d-ROMs and clinical stage. This result suggests that d-ROMs might not reflect the volume of lymphoma cells directly. Meanwhile, d-ROMs correlated significantly with both sIL-2R and IPI, which are recognized as powerful prognostic factors for DLBCL. Unfortunately, no significant difference in CR rates was seen between patients with d-ROMs $<425$ and $\geq 425 \mu \mathrm{M}$, BAP $<2,002$ and $\geq 2,002 \mu \mathrm{M}$, or $\mathrm{d}-\mathrm{ROMs} / \mathrm{BAP}<0.203$ and $\geq 0.203$. In addition, no significant differences in 3 -year OS rates were identified between patients with d-ROMs $<425$ and $\geq 425 \mu \mathrm{M}$. Similarly, no significant differences were observed for BAP and d-ROMs/BAP ratio. However, multivariate analysis revealed d-ROMs as an independent prognostic factor for DLBCL patients in PFS. This result showed that oxidative stress may impact prognosis in DLBCL patients. At the same time, we should discuss the discrepancy between the results from uni- and multivariate analyses. We considered that some differences in background characteristics exist between high- and low-d-ROMs patients. Such differences in background may have contributed to 
discrepancies between results from uni- and multivariate analyses. If we could match backgrounds between high- and low-d-ROMs patients, univariate analyses might reveal some significant differences. Multivariate analysis offers a useful method to address the issue of differences in background characteristics. Indeed, the present study found significant deviations in LDH, B symptoms, and sIL-2R (data not shown). To clarify these problems, prospective studies are required. Recently, Nojima et al (28) reported the role of oxidative stress in DLBCL. They measured d-ROMs and BAP in patients with non-Hodgkin's lymphoma (NHL), similar to our study. Defining oxidation stress index (OSI) as $\mathrm{OSI}=\mathrm{C} \times \mathrm{x}$ (d-ROMs/BAP), where $\mathrm{C}$ denotes a coefficient for standardization to set the mean OSI in healthy individuals at 1.0), they reported OSI as significantly higher in DLBCL patients with advanced clinical stage compared to localized stage. They therefore claimed that the OSI might offer a useful clinical marker for NHL. However, they did not show differences in either $\mathrm{CR}$ rates or survival rates according to oxidative stress.

The issue of d-ROMs and BAP in lymphoma tissue is very interesting, but unfortunately we did not measure these concentrations in lymphoid tumor tissue. We therefore could not clarify the associations between d-ROMs and BAP concentrations in lymphoma tissue and serum. We consider that d-ROMs and BAP concentrations in lymphoid tumor tissue may correlate with serum concentrations, but serum concentrations of d-ROMs and BAP may also reflect immune responses of the whole body to lymphoid malignancies. Measurement of d-ROMs and BAP concentrations in lymphoid tumor tissue may clarify which cells produce the oxidative stress and the mechanisms by which oxidative stress affects the carcinogenesis of DLBCL.

In the present study, cases with high LDH levels showed higher levels of d-ROMs than those with low LDH levels. This may indicate that LDH reflects global dynamic metabolic reactions, including ROS. In addition, a previous study of population-based cohorts found that levels of d-ROMs were strongly associated with cancer mortality (46). In the present study, concentrations of d-ROMs were significantly higher in DLBCL patients than in healthy volunteers, and oxidative stress may also be associated with an increased risk of DLBCL (47).

In conclusion, levels of d-ROMs were significantly higher in DLBCL patients than in healthy volunteers. Although univariate analysis revealed that oxidative stress did not impact the prognosis of untreated patients with DLBCL, multivariate analysis revealed $\mathrm{d}-\mathrm{ROMs}$ as an independent prognostic factor for DLBCL patients in PFS. These results showed that oxidative stress plays important roles in carcinogenesis for DLBCL patients.

\section{Acknowledgements}

The authors would like to thank the participating physicians, Dr Yoshikazu Ikoma, Dr Kaneda Yuto, Dr Kimihiro Yamaguchi and Dr Eri Takada. The authors are also grateful to Ms. Chiyoko Sano, Ms. Hitomi Fujisawa, Ms. Miho Yagi and Ms. Eriko Kunishima (all First Department of Internal Medicine, Gifu University Graduate School of Medicine, Gifu, Japan) for their administrative and technical assistance. This abstract was presented at the 17th Japanese Society of Medical Oncology
Annual Meeting (July 18-20, 2019 in Kyoto, Japan) and was published as Abstract no. P3-085.

\section{Funding}

No funding was received.

\section{Availability of data and materials}

The datasets used and/or analyzed during the current study are available from the corresponding author on reasonable request.

\section{Authors' contributions}

HT, MS and TH designed the present study. HN, RM, TM, NN, JK and YK developed the methodology and assessed the authenticity of the raw data. TM, NN, SN, JK, YK, TsT, TM and TaT provided resources. HN, SN, NN, NK, TsT, TM and TaT performed the experiments. $\mathrm{HN}$ and $\mathrm{TH}$ wrote the original draft. MS and HT reviewed and edited the manuscript. All authors read and approved the final version of the manuscript.

\section{Ethics approval and consent to participate}

Investigations were performed in compliance with the principles of good clinical practice outlined in the Declaration of Helsinki and federal guidelines, and had approval by the Medical Review Board of Gifu University Graduate School of Medicine, Gifu, Japan (approval no. 2018-003). Written informed consent was obtained from each participant.

\section{Patient consent for publication}

Consent for publication was obtained from any individual person whose data are included in this manuscript.

\section{Competing interests}

The authors declare that they have no competing interests.

\section{References}

1. Swerdlow SH, Campo E, Harris NL, Jaffe ES, Pileri SA, Stein H, (eds): WHO Classification of Tumours of Haematopoietic and Lymphoid Tissues. IARC Press, Lyon, pp 291-297, 2017.

2. Yamamoto Y, Goto N, Takemura M, Yamasuge W, Yabe K, Takami T, Miyazaki T, Takeuchi T, Shiraki M, Shimizu M, et al: Association between increased serum GP88 (progranulin) concentrations and prognosis in patients with malignant lymphomas. Clin Chim Acta 473: 139-146, 2017.

3. Nakamura N, Hara T, Shibata Y, Matsumoto T, Nakamura H, Ninomiya S, Kito Y, Kitagawa J, Kanemura N, Goto N, et al: Sarcopenia is an independent prognostic factor in male patients with diffuse large B-cell lymphoma. Ann Hematol 94: 2043-2053, 2015.

4. Nakamura N, Goto N, Tsurumi H, Takemura M, Kanemura N, Kasahara S, Hara T, Yasuda I, Shimizu M, Sawada M, et al: Serum level of soluble tumor necrosis factor receptor 2 is associated with the outcome of patients with diffuse large B-cell lymphoma treated with the R-CHOP regimen. Eur J Haematol 91: 322-331, 2013.

5. Goto N, Tsurumi H, Takemura M, Kanemura N, Kasahara S, Hara T, Yasuda I, Shimizu M, Yamada T, Sawada M, et al: Serum soluble CD27 level is associated with outcome in patients with diffuse large B-cell lymphoma treated with rituximab, cyclophosphamide, doxorubicin, vincristine and prednisolone. Leuk Lymphoma 53: 1494-1500, 2012. 
6. Goto N, Tsurumi H, Goto H, Shimomura YI, Kasahara S, Hara T, Yasuda I, Shimizu M, Murakami N, Yoshikawa T, et al: Serum soluble interleukin-2 receptor (sIL-2R) level is associated with the outcome of patients with diffuse large B cell lymphoma treated with R-CHOP regimens. Ann Hematol 91: 705-714, 2012.

7. Ninomiya S, Hara T, Tsurumi H, Goto N, Saito K, Seishima M, Takami $\mathrm{T}$ and Moriwaki $\mathrm{H}$ : Indoleamine 2,3-dioxygenase expression and serum kynurenine concentrations in patients with diffuse large B-cell lymphoma. Leuk Lymphoma 53: 1143-1145, 2012.

8. Goto N, Tsurumi H, Kasahara S, Kanemura N, Hara T, Yasuda I, Shimizu M, Murakami N, Sawada M, Yamada T, et al: Serum interleukin-18 level is associated with the outcome of patients with diffuse large B-cell lymphoma treated with CHOP or R-CHOP regimens. Eur J Haematol 87: 217-227, 2011

9. Ninomiya S, Hara T, Tsurumi H, Hoshi M, Kanemura N, Goto N, Kasahara S, Shimizu M, Ito H, Saito K, et al: Indoleamine 2,3-dioxygenase in tumor tissue indicates prognosis in patients with diffuse large B-cell lymphoma treated with R-CHOP. Ann Hematol 90: 409-416, 2011

10. Yoshikawa T, Hara T, Tsurumi H, Goto N, Hoshi M, Kitagawa J, Kanemura N, Kasahara S, Ito H, Takemura M, et al: Serum concentration of L-kynurenine predicts the clinical outcome of patients with diffuse large B-cell lymphoma treated with R-CHOP. Eur J Haematol 84: 304-309, 2010.

11. Hara T, Tsurumi H, Goto N, Kanemura N, Yoshikawa T, Kasahara S, Yamada T, Sawada M, Goto H, Fukuno K, et al: Serum soluble Fas level determines clinical outcome of patients with diffuse large B-cell lymphoma treated with CHOP and R-CHOP. J Cancer Res Clin Oncol 135: 1421-1428, 2009 .

12. Kojima Y, Tsurumi H, Goto N, Shimizu M, Kasahara S, Yamada T, Kanemura N, Hara T, Sawada M, Saio M, et al: Fas and Fas ligand expression on germinal center type-diffuse large B-cell lymphoma is associated with the clinical outcome. Eur J Haematol 76: 465-472, 2006

13. Watanuki-Miyauchi R1, Kojima Y, Tsurumi H, Hara T, Goto N, Kasahara S, Saio M, Moriwaki H and Takami T: Expression of survivin and of antigen detected by a novel monoclonal antibody, T332, is associated with outcome of diffuse large B-cell lymphoma and its subtypes. Pathol Int 55: 324-330, 2005.

14. International Non-Hodgkin's Lymphoma Prognostic Factors Project: A predictive model for aggressive non-Hodgkin's lymphoma. N Engl J Med 329: 987-994, 1993.

15. Sehn LH, Berry B, Chhanabhai M, Fitzgerald C, Gill K, Hoskins P, Klasa R, Savage KJ, Shenkier T, Sutherland J, et al: The revised International Prognostic Index(R-IPI)is a better predictor of outcome than the standard IPI for patients with diffuse large B-cell lymphoma treated with R-CHOP. Blood 109: $1857-1861,2007$

16. Gorrini C, Harris IS and Mak TW: Modulation of oxidative stress as an anticancer strategy. Nat Rev Drug Discov 12: 931-947, 2013

17. Salzman R, Pácal L, Kaňková K, Tomandl J, Horáková Z, Tóthová E and Kostřica R: High perioperative level of oxidative stress as a prognostic tool for identifying patients with a high risk of recurrence of head and neck squamous cell carcinoma. Int J Clin Oncol 15: 565-570, 2010.

18. Cesarone MR, Belcaro G, Carratelli M, Cornelli U, De Sanctis MT, Incandela L, Barsotti A, Terranova R and Nicolaides A: A simple test to monitor oxidative stress. Int Angiol 18: 127-130, 1999.

19. Trotti R, Carratelli M and Barbieri M: Performance and clinical application of a new, fast method for the detection of hydroperoxides in serum. Panminerva Med 44: 37-40, 2002.

20. Hirose H, Kawabe H, Komiya N and Saito I: Relations between serum reactive oxygen metabolites (ROMs) and various inflammatory and metabolic parameters in a Japanese population. J Atheroscler Thromb 16: 77-82, 2009.

21. Tsukioka T, Nishiyama N, Iwata T, Nagano K, Tei K and Suehiro S: Preoperative serum oxidative stress marker as a strong indicator of nodal involvement in clinical stage I lung adenocarcinoma. Int J Clin Oncol 17: 250-255, 2012.

22. Miyazaki T, Takagi K, Mine M, Yamasaki N, Tsuchiya T, Matsumoto K, Hatachi G, Izumino H, Doi R, Machino R and Nagayasu T: Video-assisted thoracic surgery attenuates perioperative oxidative stress response in lung cancer patients: A preliminary study. Acta Med Nagasaki 59: 19-25, 2014.
23. Gencer M, Ceylan E, Aksoy N and Uzun K: Association of serum reactive oxygen metabolite levels with different histopathological types of lung cancer. Respiration 73: 520-524, 2006.

24. Suzuki Y, Imai K, Takai K, Hanai T, Hayashi H, Naiki T, Nishigaki $Y$, Tomita E, Shimizu $M$ and Moriwaki $H$ : Hepatocellular carcinoma patients with increased oxidative stress levels are prone to recurrence after curative treatment: A prospective case series study using the d-ROM test. J Cancer Res Clin Oncol 139: 845-852, 2013.

25. Sasaki Y: Does oxidative stress participate in the development of hepatocellular carcinoma? J Gastroenterol 41: 1135-1148, 2006.

26. Inokuma T, Haraguchi M, Fujita F, Tajima Y and Kanematsu T: Oxidative stress and tumor progression in colorectal cancer. Hepatogastroenterology 56: 343-347, 2009.

27. Hou D, Liu Z, Xu X, Liu Q, Zhang X, Kong B, Wei JJ, Gong Y and Shao C: Increased oxidative stress mediates the antitumor effect of PARP inhibition in ovarian cancer. Redox Biol 17: 99-111, 2018.

28. Nojima J, Motoki Y, Tsuneoka H, Kuratsune H, Matsui T, Yamamoto M, Yanagihara M, Hinoda Y and Ichihara K: 'Oxidation stress index' as a possible clinical marker for the evaluation of non-Hodgkin lymphoma. Br J Haematol 155: 528-530, 2011.

29. Jaffe ES, Harris NL, Stein H and Vardiman JW: World Health Organization classification of tumors, pathology and genetics tumors of haematopoietic and lymphoid tissues. IARC Press, Lyon, pp 109-236, 2001.

30. Sugiura T, Dohi Y, Takase H, Yamashita S, Tanaka S and Kimura G: Increased reactive oxygen metabolites is associated with cardiovascular risk factors and vascular endothelial damage in middle-aged Japanese subjects. Vasc Health Risk Manag 7: 475-482, 2011.

31. Kakita H, Hussein MH, Daoud GA, Kato T, Murai H, Sugiura T, Mizuno K, Yamada Y, Ito T, Fukuda S, et al: Total hydroperoxide and biological antioxidant potentials in a neonatal sepsis model. Pediatr Res 60: 675-679, 2006

32. Takagi T and Oguro M: (2'-R)-4'-o-tetrahydropyranyladriamycin, a new anthracycline derivative; its effectiveness in lymphoid malignancies. Cancer Chemother Pharmacol 20: 151-154, 1987.

33. Miller AA and Salewski E: Prospects for pirarubicin. Med Pediatr Oncol 22: 261-268, 1994.

34. Tsurumi H, Yamada T, Sawada M, Kasahara S, Kanemura N, Kojima Y, Fukuno K, Hara T, Saio M, Takahashi T, et al: Biweekly CHOP or THP-COP regimens in the treatment of newly diagnosed aggressive non-Hodgkin's lymphoma. A comparison of doxorubicin and pirarubicin: A randomized phase II study. J Cancer Res Clin Oncol 130: 107-113, 2004.

35. Hara T, Tsurumi H, Goto N, Kitagawa J, Kanemura N, Yoshikawa T, Kasahara S, Goto H, Fukuno K, Yamada T, et al: Phase II study of Rituximab combined with THP-COP as first-line therapy for patients younger than 70 years with diffuse large B cell lymphoma. J Cancer Res Clin Oncol 136: 65-70, 2010.

36. Kasahara S, Hara T, Tsurumi H, Goto N, Kitagawa J, Kanemura N, Yoshikawa T, Goto H, Fukuno K, Yamada T, et al: Phase II study of the tetrahydropyranyl adriamycin-cyclophosphamide, vincristine, and prednisolone regimen combined with rituximab as first-line treatment for elderly patients with diffuse large B-cell lymphoma. Leuk Lymphoma 52: 629-634, 2011.

37. Hara T, Yoshikawa T, Goto H, Sawada M, Yamada T, Fukuno K, Kasahara S, Shibata Y, Matsumoto T, Mabuchi R, et al: R-THP-COP versus R-CHOP in patients younger than 70 years with untreated diffuse large B-cell lymphoma: A randomized, open-label, non-inferiority phase 3 trial. Hematol Oncol 36: 638-644, 2018.

38. Sawada M, Tsurumi H, Yamada T, Hara T, Fukuno K, Goto H, Shimizu M, Kasahara S, Yoshikawa T, Kanemura N, et al: A prospective study of P-IMVP-16/CBDCA: A novel salvage chemotherapy for patients with aggressive non-Hodgkin's lymphoma who had previously received CHOP therapy as first-line chemotherapy. Eur J Haematol 68: 354-361, 2002.

39. Matsumoto T, Hara T, Shibata Y, Nakamura N, Nakamura $H$, Ninomiya S, Kitagawa J, Kanemura N, Goto N, Kito Y, et al: A salvage chemotherapy of R-P-IMVP16/CBDCA consisting of rituximab, methylprednisolone, ifosfamide, methotrexate, etoposide, and carboplatin for patients with diffuse large B cell lymphoma who had previously received R-CHOP therapy as first-line chemotherapy. Hematol Oncol 35: 288-295, 2017.

40. Cheson BD, Pfistner B, Juweid ME, Gascoyne RD, Specht L, Horning SJ, Coiffier B, Fisher RI, Hagenbeek A, Zucca E, et al: Revised response criteria for malignant lymphoma. J Clin Oncol 25: 579-586, 2007. 
41. Kaplan EL and Meier P: Nonparametric estimation from incomplete observations. J Am Stat Assoc 53: 457-481, 1958.

42. Valko M, Leibfritz D, Moncol J, Cronin MT, Mazur M and Telser J: Free radicals and antioxidants in normal physiological functions and human disease. Int J Biochem Cell Biol 39: 44-84, 2007.

43. Bjelland S and Seeberg E: Mutagenicity, toxicity and repair of DNA base damage induced by oxidation. Mutat Res 531: 37-80, 2003.

44. Kryston TB, Georgiev AB, Pissis P and Georgakilas AG: Role of oxidative stress and DNA damage in human carcinogenesis. Mutat Res 711: 193-201, 2011.

45. Schöttker B, Saum KU, Jansen EH, Boffetta P, Trichopoulou A, Holleczek B, Dieffenbach AK and Brenner H: Oxidative stress markers and all-cause mortality at older age: A population-based cohort study. J Gerontol A Biol Sci Med Sci 70: 518-524, 2015.
46. Schöttker B, Brenner H, Jansen EH, Gardiner J, Peasey A, Kubínová R, Pająk A, Topor-Madry R, Tamosiunas A, Saum KU, et al: Evidence for the free radical/oxidative stress theory of ageing from the CHANCES consortium: A meta-analysis of individual participant data. BMC Med 13: 300, 2015.

47. Lan Q, Zheng T, Shen M, Zhang Y, Wang SS, Zahm SH, Holford TR, Leaderer B, Boyle P and Chanock S: Genetic polymorphisms in the oxidative stress pathway and susceptibility to non-Hodgkin lymphoma. Hum Genet 121: 161-168, 2007. 